\title{
Peripherally inserted central venous catheter: an alternative for improving the quality of nursing care
}

\author{
Prof. Braga PhD, Luciene, University of Lisbon, Coimbra, Portugal \\ Prof. Salgueiro-Oliveira PhD, Anabela, Higher School of Nursing, Coimbra, Portugal (Presenting author) \\ Prof. Arreguy-Sena PhD, Cristina, Universidade Federal de Juiz de Fora, Juiz de Fora, Brazil \\ Prof. Parreira PhD, Pedro, Higher School of Nursing, Coimbra, Portugal
}

Introduction: Evidence suggests high rates of complications related to the peripheral venous catheter (PVC). Among causes is the administration of irritant/vesicant medicine, with $\mathrm{pH} \leq 5$ or $\geq 9$ and osmolarity $\geq 900 \mathrm{mOsm} / \mathrm{L}^{(1-2)}$ These risk factors are indications for using peripherally inserted central venous catheters (PICC) ${ }^{(3-4)}$. However, safely using PICC requires the acquisition of knowledge (4).

Objective: To analyze the cumulative incidence of complications in Portuguese patients with PICC or PVC after implementing an educational intervention on care with PICC.

Method: A theoretical and practical educational intervention with nurses of a service of medicine of Portugal, on care for patients in the insertion, maintenance and monitoring of the PICC. A cohort pilot study was held during 40 consecutive days, in 2016. Patients included were adults: nine patients with PICC and 36 with PVC. Descriptive statistical analysis was performed.

\section{Results: Complication PICC:}

- Obstruction - 22.2\%

\section{Complications PVC:}

- Accidental removal of the catheter by the patient $-47.2 \%$

- Infiltration - $38.8 \%$

- Fluid leakage on the insertion site $36.1 \%$

- Obstruction - 27.7\%

- Phlebitis - 22.2\%

- Pain on the insertion site $-5.5 \%$

Discussion \& Conclusion: Permanent education is essential to improve nurses' knowledge of PICC care, and is a strategy to achieve higher levels of qualification and the transformation of practices $^{(5)}$. PICC showed a lower incidence of complications when compared to the PVC, becoming a favorable alternative to improve the quality of nursing care to patients who have a medical indication for PICC. Ensuring the criteria of selection of a venous catheter is essential in order to reduce complications, improve the results of nursing care and promote the patients' well-being ${ }^{(3-4)}$.

\section{References:}

1-Braga LM et al. Phlebitis and infiltration: vascular trauma associated with peripheral catheter. Rev Lat-Am Enf.2018;26:26:e3002.

2-Salgueiro-Oliveira A et al. Incidence of phlebitis in patients with peripheral intravenous catheters: the influence of some risk factors. Aust J Adv Nurs.2012;30(2):32-9.

3-Chopra $\mathrm{V}$ et al. The Michigan appropriateness guide for intravenous catheters: results from a multispecialty panel using the RAND/UCLA appropriateness method. Ann Intern Med 2015;163(6 Suppl.):S1-40.

4-Infusion Nurses Society. Infusion therapy standards of practice. J Infus Nurs.2016;39(1S):S1-160.

5 -Harrod $\mathrm{M}$ et al. Challenges for nurses caring for individuals with peripherally inserted central catheters in skilled nursing facilities. J Am Geriatr Soc.2016;64(10):2059-64. 